Еренков О. Ю., Рожков А. И., Козиев А. М.

O. Yu. Erenkov, A. I. Rozhkov, A. M. Koziev

ПОЛУЧЕНИЕ СТЕКЛОПЛАСТИКА ПОВЫШЕННОЙ ПРОЧНОСТИ

\title{
PRODUCTION OF HIGH STRENGTH FIBERGLASS
}

Еренков Олег Юрьевич - доктор технических наук, профессор кафедры «Машины и аппараты химических производств» ФГБОУ ВО «Комсомольский-на-Амуре государственный технический университет» (Россия, г. Комсомольск-на-Амуре), профессор кафедры «Химическая технология и биотехнология» ФГБОУ ВО «Тихоокеанский государственный университет» (Россия, г. Хабаровск). E-mail: Erenkov@list.ru. Mr. Oleg Yu. Erenkov - D.Sc. in engineering, professor, Department of Chemical Industry Machinery and Equipment, Komsomolsk-on-Amur State Technical University (Russia, Komsomolsk-on-Amur), professor of the Chemical Technology Department, Pacific National University (Russia, Khabarovsk). E-mail: erenkov@list.ru.

Рожков Артур Игоревич - магистрант кафедры «Машины и аппараты химических производств» ФГБОУ ВО «Комсомольский-на-Амуре государственный технический университет» (Россия, г. Комсомольск-наАмype). E-mail: artur-90_90@mail.ru.

Mr. Artur I. Rozhkov - Master's degree student, Chemical Industry Machinery and Equipment Department, Komsomolsk-on-Amur State Technical University (Russia, Komsomolsk-on-Amur). E-mail: artur-90_90@mail.ru.

Козиев Афзалшох Мирзоевич - магистрант кафедры «Машины и аппараты химических производств» ФГБОУ ВО «Комсомольский-на-Амуре государственный технический университет» (Россия, г. Комсомольск-на-Амуре). E-mail: erenkov@list.ru.

Mr. Afzalshokh M. Koziev - Master's degree student, Chemical Industry Machinery and Equipment Department, Komsomolsk-on-Amur State Technical University (Russia, Komsomolsk-on-Amur). E-mail: erenkov@list.ru.

Аннотация. Представлены результаты экспериментальных исследований влияния электрофизической обработки полимерного связующего непосредственно в пресс-форме на механические характеристики стеклопластика. Приведены результаты структурных исследований и физическая их интерпретация.

Summary. The influence of electrical and physical treatment of polymer binder in the mold on the mechanical characteristics of fiberglass is investigated experimentally. Structural data are presented.

Ключевые слова: стеклопластик, полимерное связующее, надмолекулярная структура, наносекундные электромагнитные импульсы, электромагнитное поле, механические свойства.

Key words: fiberglass, polymer binder, super molecular structure, nanosecond electromagnetic pulses, electromagnetic field, mechanical properties.

\section{УДК 621.763}

\section{Введение}

Как известно из практического опыта, интенсивное применение полимерных композиционных материалов (ПКМ) для производства ответственных и высоконагруженных деталей и изделий сдерживается предельными значениями прочности материала, достигнутыми в процессе его изготовления. Прочность материала формируется под влиянием внешних и внутренних факторов. К внешним факторам относятся обеспечение стабильности параметров технологического режима, правильная эксплуатация и своевременное техническое обслуживание технологического и вспомогательного оборудования, качество исходных материалов. К внутренним факторам можно отнести специфику структурообразования полимерного материала, наличие специфичных свойств, например вынужденная эластичность, подверженность различным физико-химическим воздействиям и излучениям. 
В связи с этим задача получения полимерных композиционных материалов с повышенной прочностью является актуальной задачей, решение которой позволит снизить массоемкость машин и механизмов за счет замены части деталей и узлов из дефицитных металлических материалов и сплавов.

На сегодняшний день модификации полимерного связующего являются одним из перспективных тенденций в производстве ПКМ с комплексом физико-механических показателей, включая прочность, значения которых превышают установленные стандартами или техническими условиями. В технологии получения ПКМ известно значительное количество многообразных методов модификации эпоксидного связующего $[1 ; 2 ; 3]$. На основании анализа научно-технической информации и с учетом оценки технологичности, экономической и экологической целесообразности известных методов модификации можно обосновано выдвинуть предположение о том, что одним из эффективных способов модификации полимерных связующих является электрофизическая обработка, т.е. обработка физическими полями, в том числе электромагнитными волнами и импульсами $[4 ; 5]$. Данное предположение в полной мере экспериментально подтверждено результатами проведенных исследований физико-механических свойств армированного полимерного материала типа стеклопластика [6; 7]. Установлено экспериментальным путем повышение комплекса прочностных свойств изделий из исследуемого стеклопластика до 1,7 раз после осуществления предварительной электрофизической обработки полимерного связующего наносекундными электромагнитными импульсами (НЭМИ) и одновременно электромагнитным переменным полем (ЭМП).

\section{Экспериментальные исследования}

Цель исследования - установить экспериментально взаимосвязь между значениями комплекса прочностных показателей стеклопластика и параметрами электрофизической обработки полимерного связующего непосредственно в форме для изготовления лопатки рабочего колеса центробежной компрессорной установки во время технологического процесса формования детали.

Схема и фотография экспериментальной установки представлены на рис. 1. Параметры электрофизической обработки связующего поддерживались такими же, как в работе [7].

a)

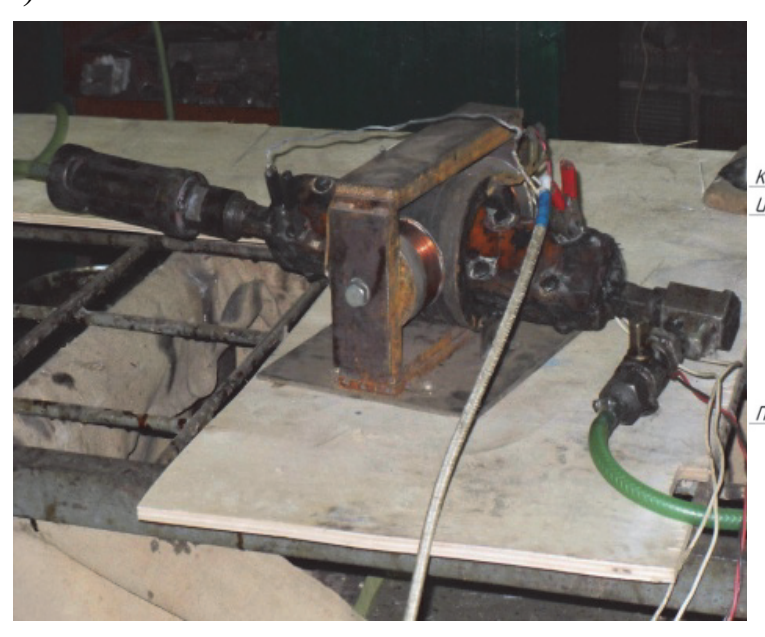

б)

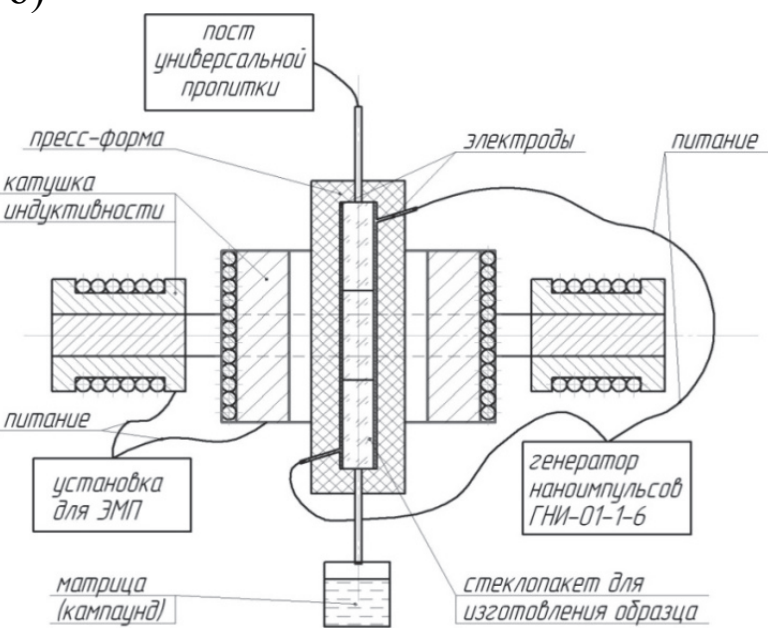

Рис. 1. Схема и общий вид экспериментальной установки

На рис. 2 - 5 представлены экспериментальные данные, позволяющие оценить взаимосвязь между видом и временем электрофизического воздействия на эпоксидное связующее Этал Т 210 и механическим характеристиками образцов из стеклопластика Этал Т 210-Т11-ГВС9. 


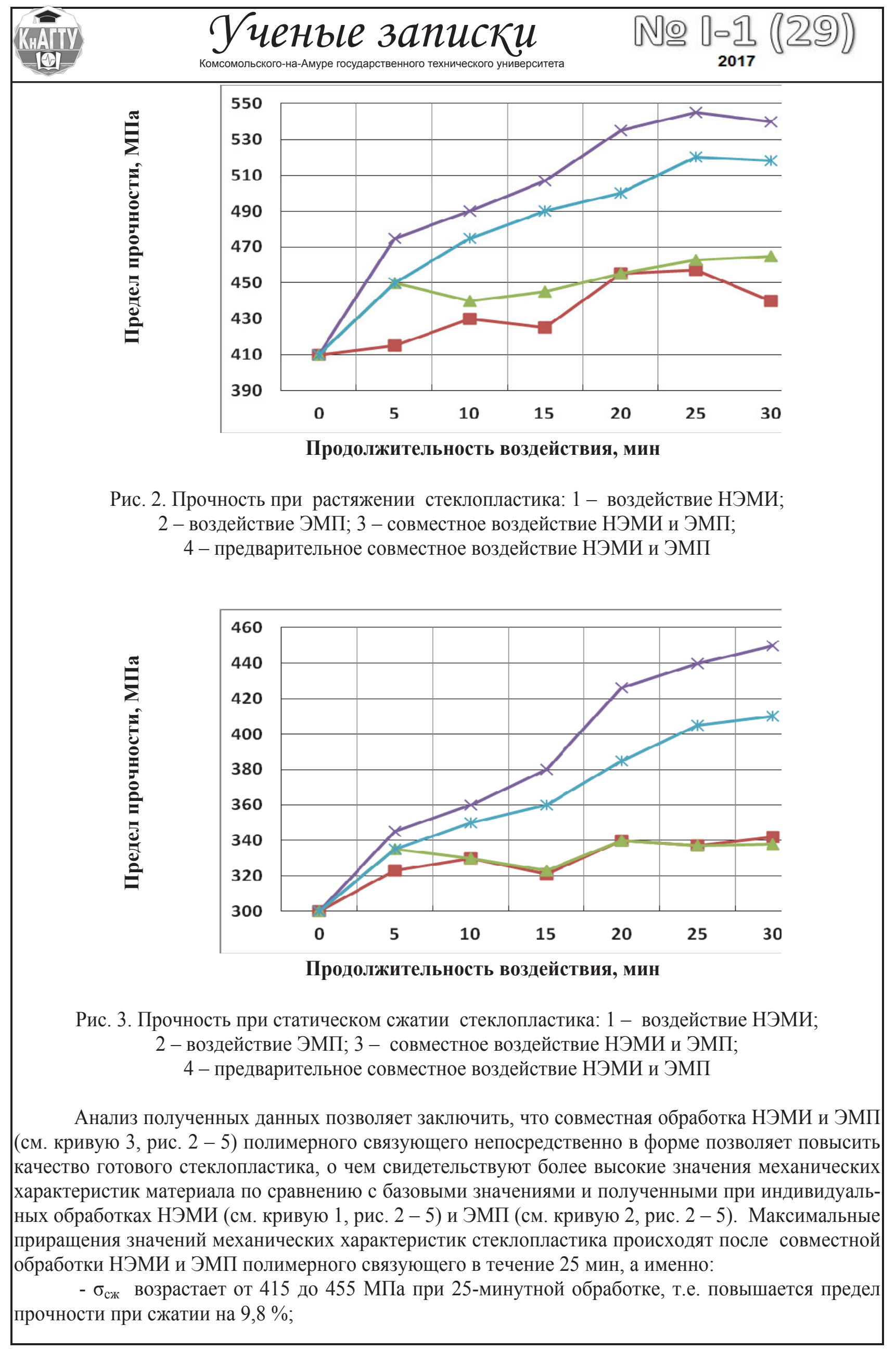




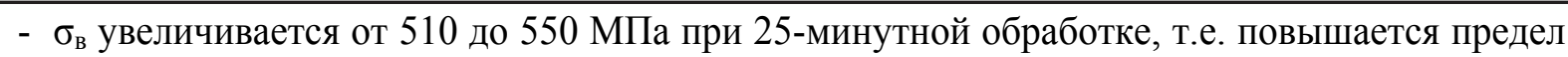
прочности при растяжении на 7,3\%;

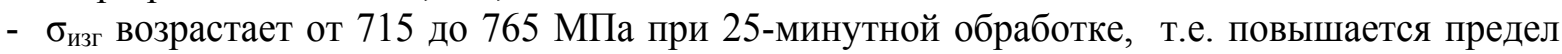
прочности при изгибе на 7,5\%;

- $\mathrm{a}_{\mathrm{H}}$ возрастает от 325 до 360 кДж/м² при 25-минутной обработке, т.е. ударная вязкость повышается на 9,8\%.

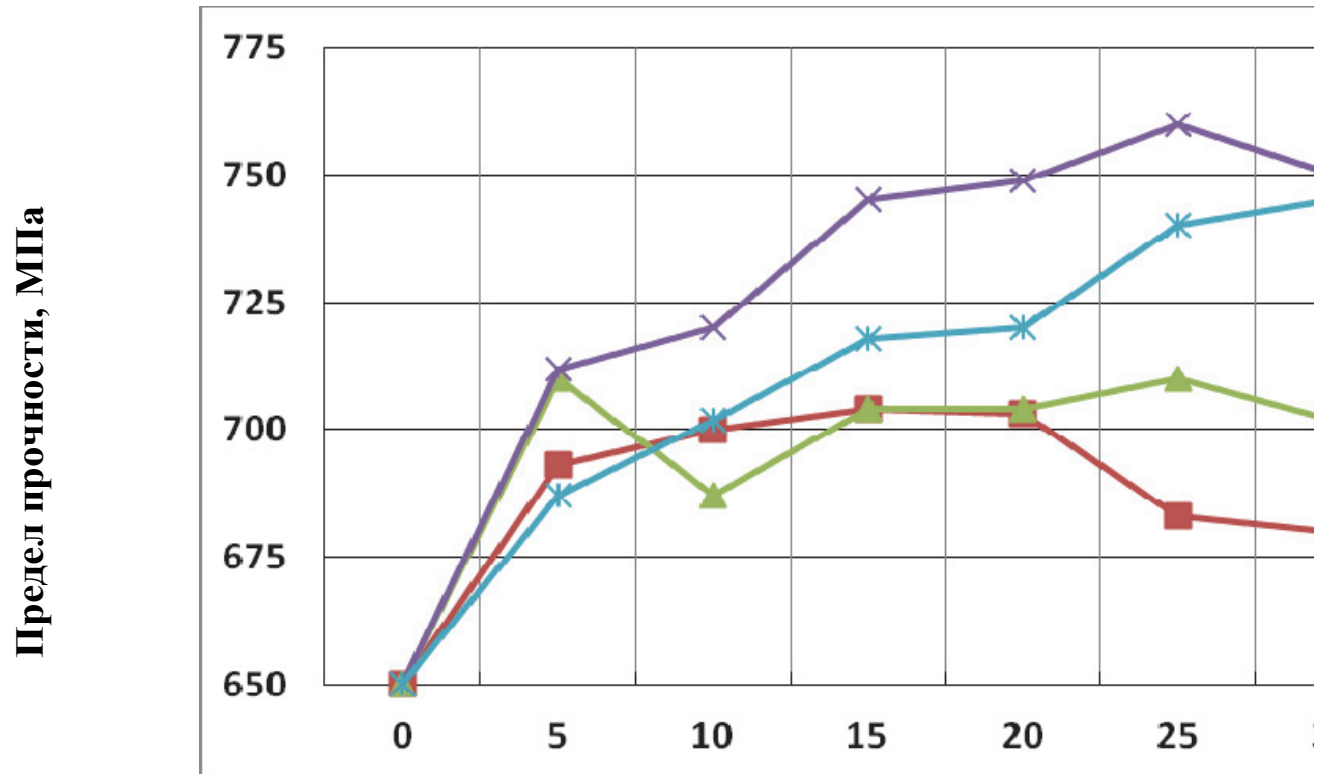

Продолжительность воздействия, мин

Рис. 4. Прочность при статическом изгибе стеклопластика: 1 - воздействие НЭМИ;

2 - воздействие ЭМП; 3 - совместное воздействие НЭМИ и ЭМП;

4 - предварительное совместное воздействие НЭМИ и ЭМП

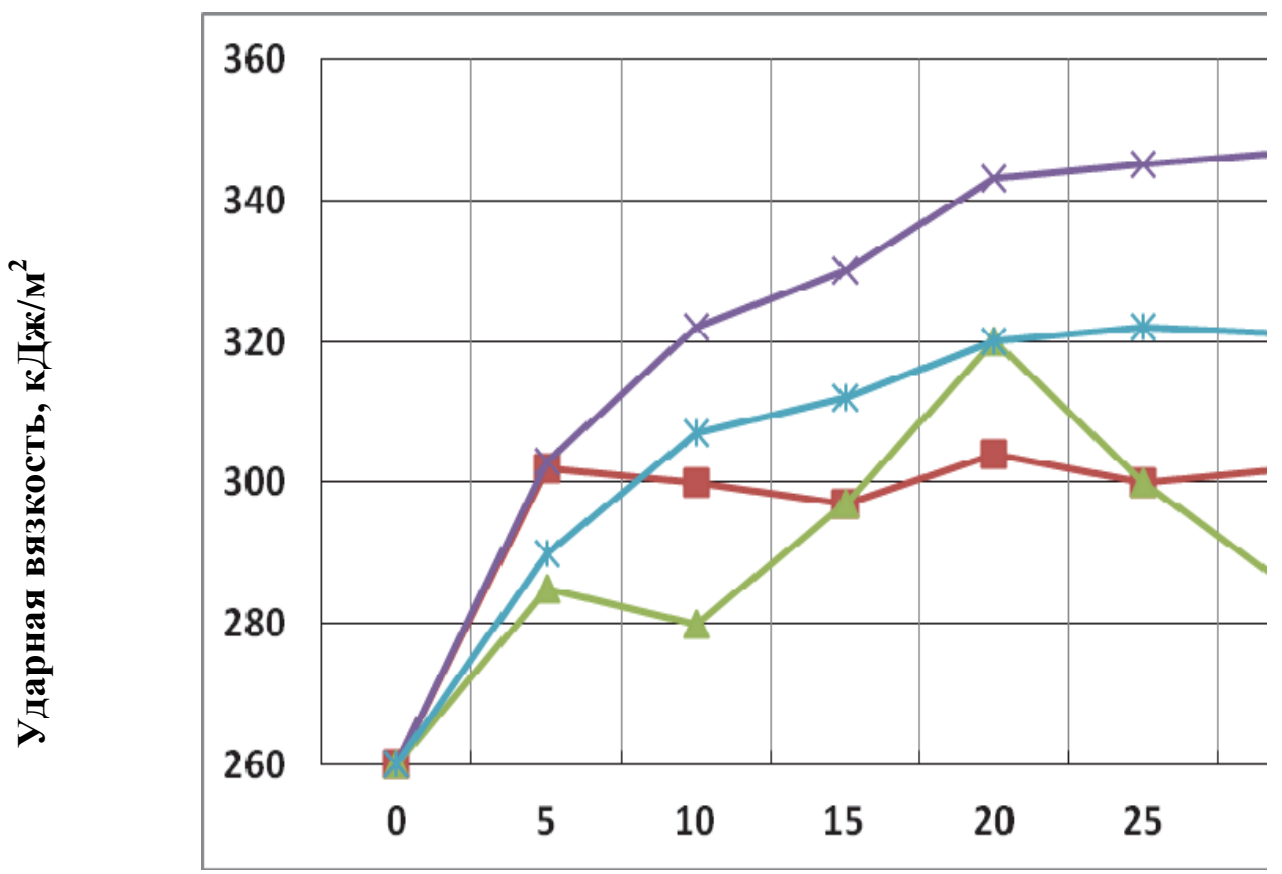

Продолжительность воздействия, мин

Рис. 5. Ударная вязкость стеклопластика: 1 - воздействие НЭМИ; 2 - воздействие ЭМП; 3 - совместное воздействие НЭМИ и ЭМП; 4 - предварительное совместное воздействие НЭМИ и ЭМП 


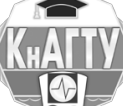

Для проведения сравнительного анализа эффективности предложенного технического решения по обработке полимерного связующего непосредственно во время формования детали на рис. 2 - 5 представлены данные (см. кривую 4) по влиянию совместной обработки связующего НЭМИ и ЭМП предварительно операции формования, полученные ранее [6]. На основании сопоставления представленных данных можно сделать заключение о том, что электрофизическая обработка полимерного связующего непосредственно в форме способствует совершенствованию технологии производства ПКМ, так реализация такого подхода позволяет получать материал с более высокими прочностными показателями и осуществлять процесс формования деталей и изделий непрерывным образом, т.е. повысить производительность технологического процесса в целом.

\section{Исследование надмолекулярной структуры полимерного связующего}

В работе проводились микроструктурные исследования образцов отвержденного полимерного связующего с целью определения характера изменения надмолекулярной структуры полимера после его электрофизической обработки совместно НЭМИ и ЭМП. Данные исследования проводились с помощью растрового электронного микроскопа марки JSM-6480.

На рис. 6, а представлены микрофотографии необработанного образца. Видно, что структура образца сферолитная, сферолиты размером от $2-6$ мкм по длине и от $2-5$ мкм по ширине, сколы рельефные, что свидетельствует о хрупком разрушении образцов. После электрофизической обработки НЭМИ и ЭМП в течение 25 мин надмолекулярная структура композитов (см. рис. 6, б) значительно меняется. В первую очередь это отражается на механизме разрушения образцов, которое происходит по пластическому механизму, т.к. сколы отличаются сглаженными границами разрушения. Во-вторых, наблюдается еще более выраженная анизотропия роста надмолекулярных образований, которые представляют собой больше фибриллярную структуру, чем сферолитную, несмотря на наличие центров кристаллизации по сферолитному типу.

Таким образом, электрофизическая обработка полимерного связующего, находящегося непосредственно в пресс-форме, совместным воздействием НЭМИ и ЭМП привела к тому, что в образцах происходит переориентация сферолитных образований в фибриллярные.

a)

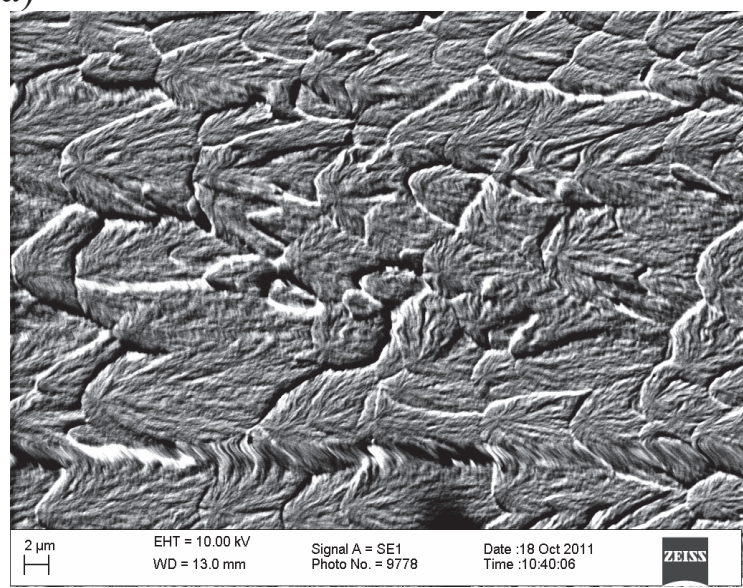

б)

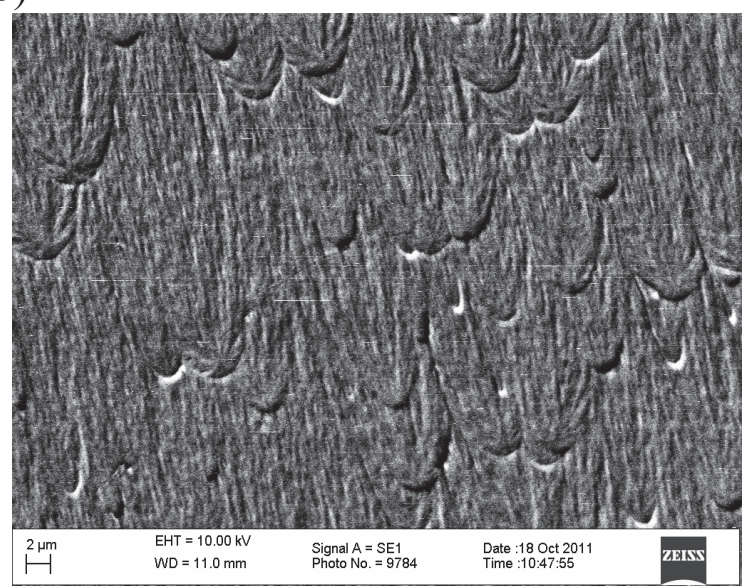

Рис. 6. Надмолекулярная структура полимерного связующего: а - до электрофизической обработки; б - после совместной обработки НЭМИ и ЭМП в течение 25 мин

\section{Физическая интерпретация полученных результатов}

Согласно дырочной концепции жидкого состояния [8] частицы жидкости находятся в гармоническом колебании около некоторого положения равновесия, при этом через некоторый промежуток времени атом может переместиться в новое положение равновесия, расположенное на близком к межатомному расстоянию. 
Воздействие НЭМИ на полимерное связующее в жидком состоянии, очевидно, способно увеличить количество атомов, обладающих избыточной энергией, необходимой для совершения акта перехода частицы из одного положения равновесия в другое. Такой переход, как известно [8; $9 ; 10]$, вызывает разрыв химических связей. При этом разрыв связей обычно сопровождается образованием на их концах радикалов, обладающих высокой реакционной способностью, что является причиной последующего восстановления разорванных химических связей. Учитывая малую длительность одного импульса, составляющую 1нс, можно предположить, что вероятности процессов разрыва связей и их восстановления будут примерно одинаковы, т.е. в некоторых случаях равновесие между актами разрыва связей и актами их восстановления несколько смещается в сторону преобладания актов разрыва, а в других случаях - в сторону преобладания актов восстановления. Таким образом, индивидуальное воздействие НЭМИ при установленных параметрах на эпоксидный олигомер в жидком состоянии не приводит к значительным изменениям его структуры и, соответственно, механических характеристик получаемого впоследствии стеклопластика.

Индивидуальное воздействие ЭМП на исследуемый эпоксидный олигомер Этал Т 210 в жидком состоянии приводит к образованию в его объеме пондеромоторных сил, т.е. сил давления электромагнитных волн на помещенное в электромагнитное поле вещество. Механизмы возникновения и действия данных сил подробно исследованы и представлены в известном труде [11]. Под действием пондеромоторных сил происходит упругое деформирование основных полимерных цепей связующего, что связано с изменением в макромолекулах межатомных расстояний и валентных углов, а также с изменением межмолекулярных расстояний за счет преодоления межмолекулярных Ван-дер-ваальсовых сил упругости.

Таким образом, должно иметь место изменение формы макромолекул связующего, т.е. изменение их конформаций. В работах $[9 ; 10]$ отмечено, что конформационные превращения макромолекул не сопровождаются разрывом химических связей. Следовательно, можно заключить, что индивидуальное воздействие ЭМП при установленных параметрах на эпоксидный олигомер в жидком состоянии не приводит к значительным изменениям его структуры и, соответственно, механических характеристик получаемого впоследствии стеклопластика.

При комбинированном воздействии НЭМИ и ЭМП одновременно имеют место, по всей вероятности, вышеописанные эффекты. Изменение конформации макромолекул с большой вероятностью позволит обеспечить интенсивное взаимодействие образующихся во время обработки НЭМИ активных радикалов и концевых групп друг с другом, образуя поперечные химические связи между макромолекулами. Это должно привести к образованию, возможно частично, пространственной структуры полимерного связующего на данной стадии производства стеклопластика. Возможность протекания реакции сшивания в полимерах до проведения технологической операции отверждения установлена, например, исследованиями [10]. При последующем отверждении связующего происходит, возможно, окончательное формирование пространственной структуры полимерного связующего. Образование пространственной структуры способствует повышению ряда физико-механических свойств конечного продукта - стеклопластика, что и подтверждается результатами экспериментальных исследований [7].

\section{Выводы}

1. Доказано экспериментально, что модификация полимерного связующего непосредственно в форме на основе совместного облучения наносекундными электромагнитными импульсами и электрическим переменным полем позволяет получать материал с более высокими, до 15 \%, прочностными показателями по сравнению с вариантом предварительной обработки и осуществлять процесс формования деталей и изделий непрерывным образом, т.е. повысить производительность технологического процесса в целом.

2. Методом растровой электронной микроскопии установлена трансформация надмолекулярной структуры полимерного связующего от сферолитной к фибриллярной после его совместной обработки наносекундными электромагнитными импульсами и электромагнитным полем. Трансформация надмолекулярной структуры полимерного связующего приводит к образованию 
пространственной структуры, что способствует повышению ряда физико-механических свойств конечного продукта - стеклопластика.

3. Применение полученного стеклопластика с повышенной прочностью открывает широкие перспективы изготовления и использования деталей и изделий, трубопроводных систем в производственной деятельности машиностроительных, авиа и судостроительных предприятий, нефтегазоперерабатывающих производств.

\section{ЛИТЕРАТУРА}

1. Кулезнев, В. Н. Химия и физика полимеров / В. Н. Кулезнев, В. А. Шершнев. - 2-е изд., перераб. и доп. М.: Колос, 2007. - $367 \mathrm{c}$.

2. Зеленев, Ю. В. Прогнозирование изменения физических свойств полимерных материалов при разных способах их модификации / Ю. В. Зеленев, В. И. Хромов // Пластические массы. - № 11. -2002.

3. Кестельман, В. Н. Термомагнитная обработка полимерных композиционных материалов

В. Н. Кестельман, А. Д. Стадник. - М.: НИИ-ТЭХИМ, 1989.

4. Бартенев, Г. М. Курс физики полимеров / Г. М. Бартенев, Ю. В. Зеленев. - Л.: Химия, 1976.

5. Арьев, А. М. Термоэлектрическая модификация полимерных материалов / А. М. Арьев, Ю. В. Зеленев // Наука и технология в России. - 1995. - № 9. - С. 13.

6. Еренков, О. Ю. Исследование механических свойств полимерных композитных материалов

О. Ю. Еренков, П. В. Игумнов, В. Л. Никишечкин // Вестник машиностроения. - 2010. - № 4. C. 61-63.

7. Еренков, О. Ю. Исследование эффективности влияния предварительной электрофизической обработки связующего на прочностные характеристики ПКМ / О. Ю. Еренков, В. Л. Никишечкин // Ученые записки Комсомольского-на-Амуре государственного технического университета. - 2010. - № I-1 (2). - С. 99-104.

8. Френкель, Я. И. Кинетическая теория жидкостей / Я. И. Френкель. - Л.: Наука, 1975.

9. Аскадский, А. А. Деформация полимеров / А. А. Аскадский. - М.: Химия, 1973. - 448 с.

10. Тагер, А. А. Физикохимия полимеров / А. А. Тагер. - М.: Химия, 1978. - 544 с.

11. Ландау, Л. Д. Электродинамика сплошных сред / Л. Д. Ландау, Е. М. Лифшиц. - М.: Физматгиз, 1959. $532 \mathrm{c}$. 